IZA DP No. 9253

Crime Victimisation and Subjective Well-Being:

Panel Evidence from Australia

Stéphane Mahuteau

Rong Zhu

August 2015

Forschungsinstitut zur Zukunft der Arbeit Institute for the Study of Labor 


\title{
Crime Victimisation and Subjective Well-Being: Panel Evidence from Australia
}

\author{
Stéphane Mahuteau \\ NILS, Flinders University \\ and IZA \\ Rong Zhu \\ NILS, Flinders University
}

\section{Discussion Paper No. 9253 \\ August 2015}

\author{
IZA \\ P.O. Box 7240 \\ 53072 Bonn \\ Germany \\ Phone: +49-228-3894-0 \\ Fax: +49-228-3894-180 \\ E-mail: iza@iza.org
}

Any opinions expressed here are those of the author(s) and not those of IZA. Research published in this series may include views on policy, but the institute itself takes no institutional policy positions. The IZA research network is committed to the IZA Guiding Principles of Research Integrity.

The Institute for the Study of Labor (IZA) in Bonn is a local and virtual international research center and a place of communication between science, politics and business. IZA is an independent nonprofit organization supported by Deutsche Post Foundation. The center is associated with the University of Bonn and offers a stimulating research environment through its international network, workshops and conferences, data service, project support, research visits and doctoral program. IZA engages in (i) original and internationally competitive research in all fields of labor economics, (ii) development of policy concepts, and (iii) dissemination of research results and concepts to the interested public.

IZA Discussion Papers often represent preliminary work and are circulated to encourage discussion. Citation of such a paper should account for its provisional character. A revised version may be available directly from the author. 
IZA Discussion Paper No. 9253

August 2015

\section{ABSTRACT \\ Crime Victimisation and Subjective Well-Being: Panel Evidence from Australia}

This paper estimates the effect of physical violence and property crimes on subjective wellbeing in Australia. Our methodology improves on previous contributions by (i) controlling for the endogeneity of victimisation and (ii) analysing the heterogeneous effect of victimisation along the whole distribution of well-being. Using fixed effects panel estimation, we find that both types of crimes reduce reported well-being to a large extent, with physical violence exerting a larger average effect than property crimes. Furthermore, using recently developed panel data quantile regression model with fixed effects, we show that the negative effects of both crimes are highly heterogeneous, with a monotonic decrease over the distribution of subjective well-being.

JEL Classification: $\quad$ C21, I31

Keywords: victimisation, subjective well-being, panel quantile regression

Corresponding author:

Stéphane Mahuteau

National Institute of Labour Studies

Flinders University

GPO Box 2100

Adelaide, South Australia 5001

Australia

E-mail: stephane.mahuteau@flinders.edu.au 


\section{Introduction}

The issue of crime is of major concern for the population and is often central to the political debate at elections time (Cohen, 2008). This is all the more important in Australia that OECD figures (OECD, 2010) show it has the ninth highest victimisation rate for assaults or threats $(3.4 \%)$ amongst OECD countries in 2005 (the OECD average was $2.9 \%$ ). In terms of burglary with entry, Australia was ranked fifth highest in 2005 with a rate of $2.5 \%$ (the OECD average was 1.8\%). One of the reasons why crime is of such concern to the population is that the cost of crime expands well beyond the pecuniary costs incurred by the direct victims of crime.

A number of studies have highlighted that the non-pecuniary costs of crime far outweigh the direct costs such as medical expenses, days-off work, cost of replacement of goods and money stolen to the victims, etc. (Kuroki, 2013). Anecdotally, Cornaglia et al. (2014) report evidence given at a US Senate Judiciary Committee whereby a 40-fold discrepancy was found between the pecuniary costs of crime and the population's willingness to pay to reduce crime. This discrepancy arises because crime is found to be associated with profound psychological issues. Crime affects other people because each instance of crime increases people's subjective risk of becoming a victim, thus increasing fear and anxiety (Powdthavee, 2005; Hanslmaier, 2013; Dustmann and Fasani, 2015). The psychology literature has long highlighted a significant relationship between crime and a number of psychological problems such as depression, anxiety, fear, and even post-traumatic stress disorder developed by victims and those close to them (Atkeson et al., 1982; Davis and Friedman, 1985; Norris and Kaniasty, 1992). More recently, the literature has started to investigate the relationship between psychological problems and self-assessed health and happiness. For instance, Ross (1993) and Moller (2005) find that people's subjective measure of health is negatively associated with feelings of fear and anxiety. These findings are corroborated by Moore (2006) who show that fear of crime (itself positively correlated with past victimisation) has a negative relationship with happiness (see also Davies and Hinks (2010); Staubli et al. $(2014))$.

Since crime can have significant adverse consequences for the subjective well-being of 
victims and the society as a whole, the accurate estimation of these non-pecuniary costs of crime, which are not directly measurable, cannot be overstated. This is all the more important that the fast developing economics literature shows a direct relationship between self-assessed well-being and more tangible outcomes such as labour market outcomes. For instance, Fritjers et al. (2014) find evidence in Australia that a decrease in mental health leads to a comparatively large decrease in employment (one standard deviation decrease in mental health leading to up to a 30 percentage point decrease in employment). Comparatively similar results are found in other countries by Hamilton et al. (1997), Chatterji et al. (2007, 2011) and Ojeda et al. (2010).

While there is ample evidence that direct experience of victimisation is negatively associated with people's subjective well-being, most of the studies cited above share three similar limitations. First, most of them use cross sectional data, thereby ignoring the role of unobserved individual heterogeneity. As crime events are not randomly distributed in the population, the estimated well-being effects of crimes can be misstated by comparing victims and non-victims in cross sectional data. ${ }^{1}$ Second, the comparison of the consequences of crimes against the person and against property for people's subjective well-being is relatively unexplored, as pointed out by Staubli et al. (2014). Finally, none of the existing studies has examined the potential heterogeneity in the effects of victimisation along the whole distribution of well-being.

This paper estimates the effects of crime victimisation on subjective well-being in Australia. Using data from the longitudinal Household, Income and Labour Dynamics in Australia (HILDA) survey, we use fixed effect panel estimators in order to address the issue of the confounding effects arising from the correlations between victimisation and unobserved heterogeneity. The information in HILDA about crimes against the person and property also allows us to compare the well-being effects of the two types of crimes. Furthermore, this paper contributes to the literature by being the first to investigate the heterogeneous effects of victimisation on different quantiles of the subjective well-being

\footnotetext{
${ }^{1}$ For example, people with higher unobserved ability may be less likely to be a crime victim, and in the meanwhile, have higher level of subjective well-being. The well-being effects of victimisation will thus be overstated in estimations using cross sectional data.
} 
distribution, using fixed effects quantile regression for panel data recently developed by Canay (2011).

We find that both physical violence and property crimes negatively affect the subjective well-being of Australians, and the average effect is stronger for physical violence than for property crimes. Specifically, physical violence and property crimes are associated with a decline of respectively 0.30 and 0.03 standard deviation of the SF-36 mental well-being measure. Using panel data quantile regression with fixed effects, we find strong evidence of heterogeneous links between crime victimisation and happiness. The adverse effects of both physical violence and property crimes are found to monotonically decrease in magnitude over the distribution of the well-being distribution. In other words, crime (especially violent crime) exerts a larger negative impact on well-being for individuals who already were in the lower part of the well-being distribution to start with.

Comparing with other important negative life events such as (i) serious personal injury/illness; (ii) fired or made redundant; and (iii) death of spouse or child, we show that the mean impact of physical violence on well-being is well over that of losing one's job (through being fired or made redundant) but smaller compared to experiencing the death of a spouse/child or sustaining a serious personal injury/illness. We further show that the negative effects of property crimes are smaller in magnitude than the corresponding wellbeing effects of the three other life events, throughout the whole distribution of well-being. While we find that the well-being losses due to physical crimes are smaller in magnitude than those of people suffering from severe personal injury/illness or death of spouse/child, most of the differences intervene in the lower percentiles of the well-being distribution. Past the median, the effect of violent crimes on well-being is very close to that of these two major life events.

The remaining paper is organised as follows. Section two describes the data and presents summary statistics. Section three discusses the empirical approach. Section four presents the estimation results and Section five offers concluding remarks. 


\section{Data}

\subsection{The HILDA Survey}

HILDA is the first and only large-scale, nationally representative household panel survey in Australia. Starting from 2001, HILDA annually collects rich information on people's demographics, life events, health and subjective well-being. In this study, we apply a few restrictions to the data from the HILDA Survey. First, we use the eleven waves of HILDA from 2002 to 2012, as the information about victimisation was unavailable in the first wave (2001). Second, we focus on people aged between 21 and 65. Finally, we drop observations with missing information on core variables (summarised in Table 1). Our final sample consists of 96,503 observations for 18,460 persons between the years 2002 and 2012 .

\subsection{Variables and descriptive statistics}

In HILDA, respondents were asked to report the major events that have happened in their life during the past 12 months. Of central interest to us are the two crime-related variables: (i) victim of physical violence (e.g., assault), and (ii) victim of a property crime (e.g., theft, housebreaking).

Our main measure of mental well-being is based on the 36-item Short Form Health Survey (SF-36), an internationally tested and widely used tool for measuring health (Hays et al., 1993; Hemingway et al., 1997). In each wave of HILDA, respondents were asked all SF-36 questions about their physical health and mental well-being. Out of the 36 questions, 14 fall in the category of mental well-being, which can be divided into four scales that measure different aspects and components of mental well-being: (i) Vitality (VT) (measuring fatigue and energy scales); (ii) Social Functioning (SF) (measuring social limitations); (iii) Role-Emotional (RE) (measuring limitation in work or activities due to emotional health); and (iv) Mental Health (MH) (measuring feelings of anxiety and depression). ${ }^{2}$ These four scales of mental well-being are provided in a standardized form

\footnotetext{
${ }^{2}$ There are 22 questions falling in the category of physical health, which can also be grouped into four scales: Physical Functioning (PF) (measuring limitations to daily activities), Role-Physical (RP) (measuring Limitations in work or activities caused by physical health), Bodily Pain (BP) (measuring
} 
in the HILDA Survey with a range from 0 to 100 , with higher scores indicating better mental well-being. We generate our main measure of general mental well-being for each observation by calculating an average of the four scales. This overall measure has been widely used as index of mental well-being in a number of health studies (see, for example, Flatau et al. (2000) and Fritjers et al. (2014)). We further divide this measure of general mental well-being and its four components by 10 so that they all range from 0 to $10 .^{3}$

Descriptive statistics by victimisation status are reported in Table 1. Among the 96,503 observations, 1,503 of them reported that they directly experienced physical violence in the prior 12 months, and 4,735 were victims of property crimes. ${ }^{4}$ About $20.0 \%$ (301 observations) of the 1,503 observations who were victims of physical violence were also victims of property crimes in the same year, suggesting that our empirical analysis needs to examine of the two types of crimes simultaneously to separate the well-being effect of the crime against the person from the effect of the crime against property. In addition, among the 18,460 persons in our sample, 1,077 individuals had been victims of physical violence at least once during 2002-2011 and 266 of them repeatedly reported that they were victims of physical violence across waves. 3,489 individuals had been victims of property crimes, and 900 of them experienced property crimes more than once. Out of the 1,077 victims of violence and 3,489 victims of property crimes, 448 people had been victims of both crimes during 2002-2011.

Table 1 reports the mean subjective well-being by victimisation status. We use the two-sample $t$-test to test the null hypothesis that the mean well-being is equal for victims and non-victims. Crime victims are found to report significantly lower levels of subjective well-being than non-victims, offering initial evidence of a possible link between crime and well-being. In addition, a rough comparison of the well-being between victims and nonpain and limitations therefrom) and General Health (GH) (measuring health perception).

${ }^{3}$ In Section 4.3.2, we use the life satisfaction variable as an alternative measure of general subjective well-being to check the robustness of our results. We normalize SF-36 mental well-being variables to be between 0 and 10 so that they share the same range as the life satisfaction measure, which is on an eleven-point Likert scale from 0 to 10.

${ }^{4}$ Among the 1,503 observations reporting to be victims of physical violence in the last 12 months, only 20 of them experienced this crime twice or more during the same period. Among the 4,735 observations reporting to be victims of property crimes, 46 observations experienced this crime more than once in the same year. 


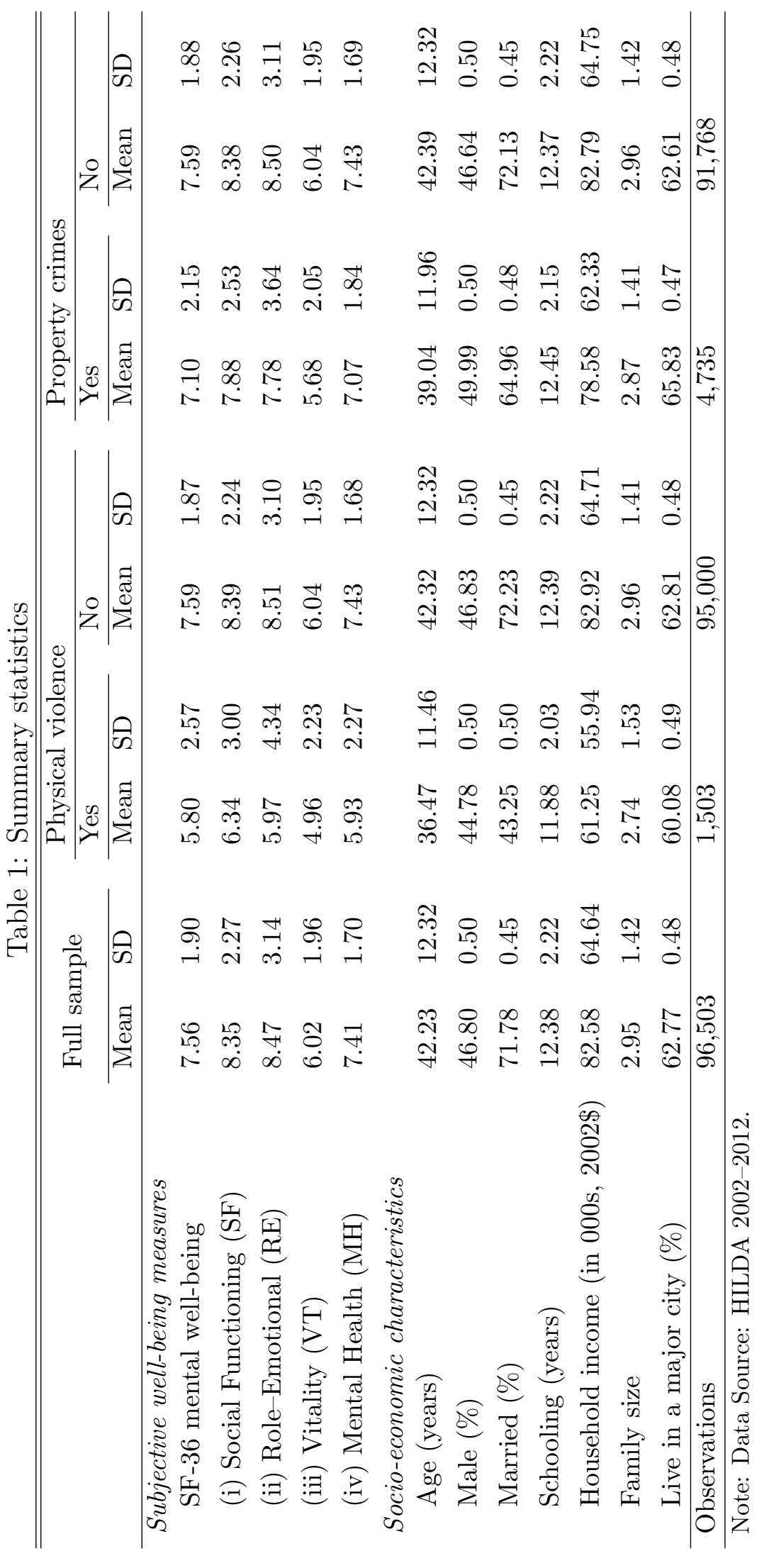


victims suggests that the adverse well-being impact may be larger for physical violence $(1.79=7.59-5.80)$ than for property crimes $(0.49=7.59-7.10)$.

Table 1 also shows that when compared with non-victims, victims are younger and less likely to be married. They also have lower household income and slightly smaller family size. There are noticeable differences in individual characteristics between victims of the two types of crime as well. Compared with victims of property crimes, victims of physical violence are, on average, two and a half years younger and five percentage points less likely to be married. Furthermore, they have received less years of education and have significantly lower household income.

\subsection{Raw distributional differences in subjective well-being be- tween crime victims and non-victims}

In Table 1 we observed that victims of crimes, on average, report significantly lower levels of subjective well-being than non-victims. One may ponder upon whether these differences persist along the whole distribution of well-being and whether crime victimisation has heterogeneous effects on people with different levels of subjective well-being. We provide tentative evidence below that the well-being differences between victims and non-victims may indeed differ at different parts of the well-being distribution.

Figure 1 presents the kernel density estimates of the SF-36 mental well-being measure for each group defined by the type of crime and victimisation status. The two-sample Kolmogorov-Smirnov test rejects the null hypothesis that the subjective well-being for victims and non-victims come from the same distribution ( $p$-value $=0.000$ for both physical violence and property crimes). Consequently, the distributions of subjective well-being for crime victims and non-victims are significantly different.

Figure 2 shows that important gaps exist between victims and non-victims at various percentiles of the well-being distribution. It also shows that the amplitude of these gaps varies noticeably along the distribution and depending on the type of crime, larger gaps prevailing for violent crimes. This gives prima facie evidence that the adverse effects of 

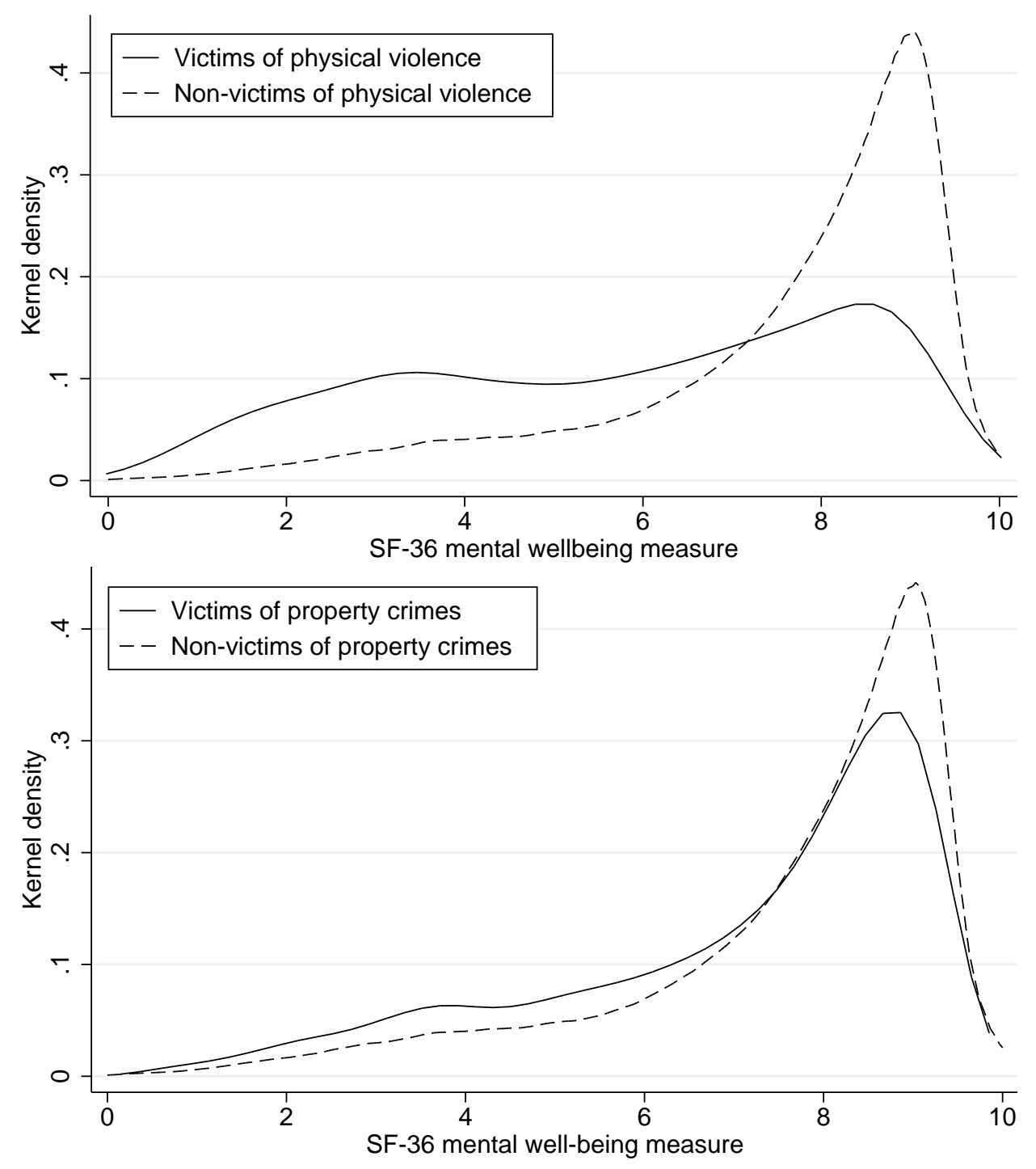

Figure 1: Kernel density estimates of SF-36 mental well-being by victimisation status 
victimisation may be felt, to a larger extent, by people at the lower end of the well-being distribution. This also suggests that focusing on mean estimates does not bring the full picture of the effects of victimisation. The distributional patterns of subjective well-being displayed in Figures 1 and 2 motivate us to conduct a distributional analysis of the effects of physical violence and property crimes on subjective well-being.
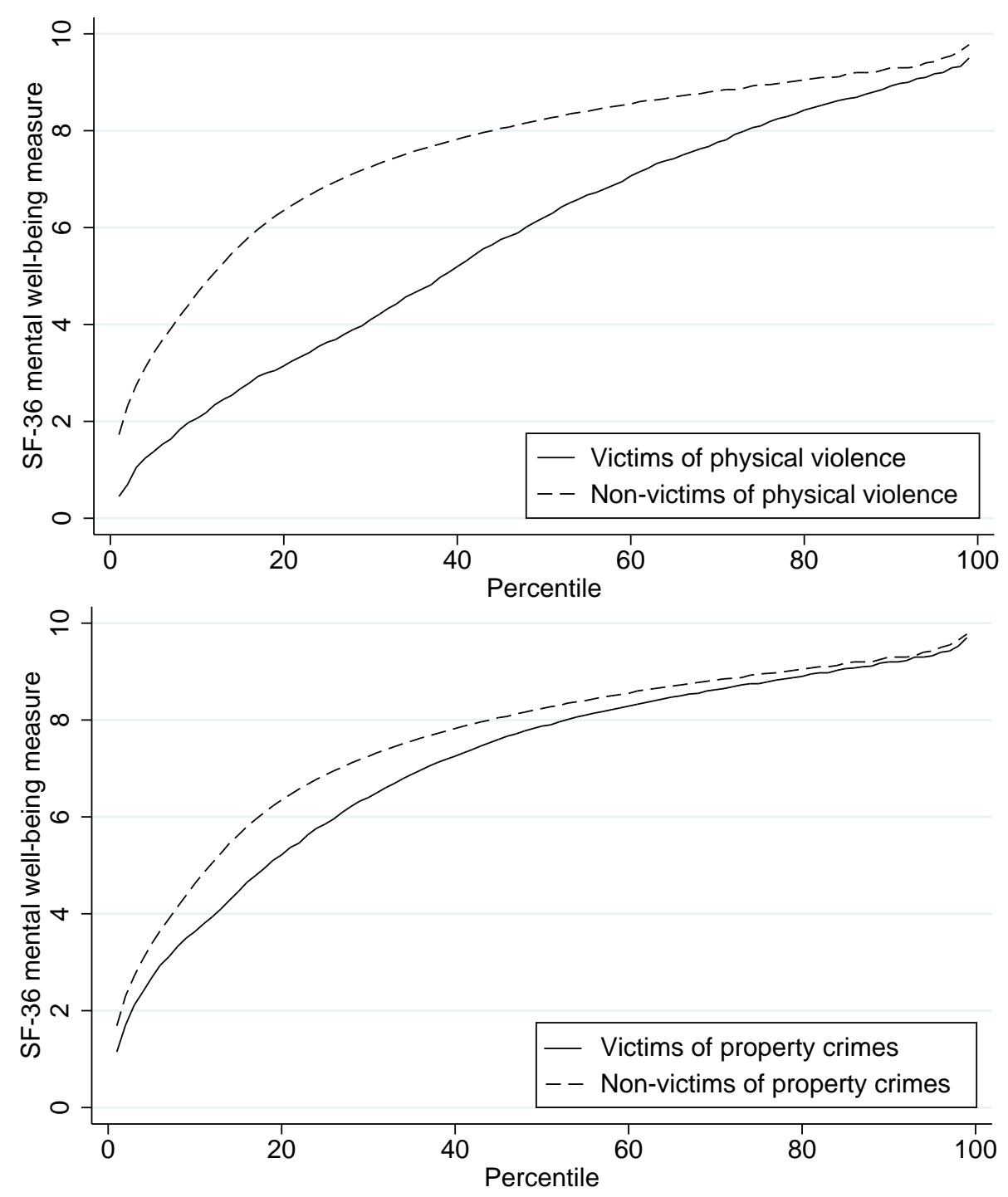

Figure 2: SF-36 mental well-being of crime victims and non-victims by percentile

\section{Empirical approach}

We consider the following equation

$$
S W B_{i t}=\text { Victim }_{1 i t} \beta_{1}+\text { Victim }_{2 i t} \beta_{2}+X_{i t}^{\prime} \gamma+u_{i}+\epsilon_{i t}
$$


where $S W B_{i t}$ denotes the subjective well-being of individual $i$ at time $t$. Victim Vit $_{1 i}$ is an indicator variable equal to one if an individual is the victim of physical violence and zero otherwise. Victim $_{2 i t}$ indicates whether one is the victim of a property crime or not. $X_{i t}$ is a vector of control variables typically related with well-being, including age, age squared, a married dummy, years of schooling, household income, number of family members, and a dummy variable indicating whether living in a major city. A full set of state of residence dummies and year dummies are also included. $u_{i}$ denotes the unobserved individual heterogeneity and $\epsilon_{i t}$ is the idiosyncratic error term.

We estimate equation (1) with fixed effects (FE) panel estimation. The within estimates of $\beta_{1}$ and $\beta_{2}$ separately measure the average effects of physical violence and property crimes on individual subjective well-being. Compared with OLS estimation, the FE panel estimation can remove the bias in $\beta_{1}$ and $\beta_{2}$ due to the unobserved individual heterogeneity $u_{i}$

To explore the heterogeneous effects of crime victimisation along the well-being distribution, we use the panel data quantile regression model with fixed effects (QR-FE) recently developed by Canay (2011). Modelling fixed effects as location shift variables, Canay (2011) shows that the QR-FE approach can be carried out in the following two steps. First, we estimate the unobserved fixed effects as $\widehat{u}_{i}=\frac{1}{T} \sum_{t=1}^{T}\left(S W B_{i t}-V_{i c t i m} \widehat{\widehat{\beta}}_{1}-\right.$ Victim $\left._{2 i t} \widehat{\beta_{2}}-X_{i t}^{\prime} \widehat{\gamma}\right)$, where $\widehat{\beta}_{1}, \widehat{\beta}_{2}$ and $\widehat{\gamma}$ are obtained from the FE panel estimation of equation (1). Second, we implement the standard conditional quantile regression approach of Koenker and Bassett (1978), using $\left(\widehat{S W} B_{i t}=S W B_{i t}-\widehat{u}_{i}\right)$ as the dependent variable. More specifically, we solve the following minimization problem

$$
\left(\widehat{\beta}_{1 \tau}, \widehat{\beta}_{2 \tau}, \widehat{\gamma}_{\tau}\right)=\arg \min _{\left(\beta_{1 \tau}, \beta_{2 \tau}, \gamma_{\tau}\right)} \frac{1}{N T} \sum_{i=1}^{N} \sum_{t=1}^{T}\left[\rho_{\tau}\left(\widehat{S W B} B_{i t}-\operatorname{Victim}_{1 i t} \beta_{1 \tau}-V_{i c t i m}{ }_{2 i t} \beta_{2 \tau}-X_{i t}^{\prime} \gamma_{\tau}\right)\right]
$$

where $\rho_{\tau}(u)=u[\tau-I(u<0)]$ and $I$ is an indicator function. $\widehat{\beta}_{1 \tau}$ and $\widehat{\beta}_{2 \tau}$ measure separately the estimated effects of Victim $_{1 i t}$ and Victim $_{2 i t}$ on the $\tau$-th percentile of the distribution of $S W B_{i t} \cdot{ }^{5}$

\footnotetext{
${ }^{5}$ Interested readers are referred to Canay (2011) for technical details.
} 


\section{Results}

\subsection{Victimisation and subjective well-being}

Table 2 reports the OLS and FE panel estimates of $\beta_{1}$ and $\beta_{2}$ in equation (1). Standard errors reported are corrected for clustering at the individual level. ${ }^{6}$ The OLS estimates show that physical violence and property crimes are both significantly associated with lower levels of mental well-being. On average, physical violence is found to be associated with a decrease of 0.81 standard deviation $(=1.537 / 1.90)$ of the SF-36 mental well-being measure. The mean effect of property crimes is smaller, associated with 0.21 standard deviation $(=0.397 / 1.90)$ decline in mental well-being. We further test whether there are any gender differences in the OLS estimates of the well-being effects of victimisation (Clogg et al., 1995). We find strong evidence that females are more negatively affected by physical violence than males, when individual heterogeneity is not accounted for in OLS estimations. However, OLS estimates suggest no gender differences in the mean well-being effects of property crimes.

Table 2: Mean effects of victimisation on subjective well-being

\begin{tabular}{cllll}
\hline \hline & All & Male & Female & H0: Male=Female \\
\hline OLS estimates & & & & \\
\hline Physical violence & $-1.537^{* * *}$ & $-1.231^{* * *}$ & $-1.776^{* * *}$ & $p=0.000$ \\
& $(0.081)$ & $(0.109)$ & $(0.111)$ & \\
Property crime & $-0.397^{* * *}$ & $-0.397^{* * *}$ & $-0.416^{* * *}$ & $p=0.790$ \\
& $(0.036)$ & $(0.050)$ & $(0.051)$ &
\end{tabular}

FE estimates

$\begin{array}{lllll}\text { Physical violence } & -0.566^{* * *} & -0.485^{* * *} & -0.637^{* * *} & p=0.193 \\ & (0.059) & (0.079) & (0.086) & \\ \text { Property crime } & -0.066^{* * *} & -0.054^{*} & -0.078^{* *} & p=0.603\end{array}$

$(0.023) \quad(0.030) \quad(0.035)$

Note: Control variables include age, age squared, a married dummy, years of schooling, household income, number of family members, and a dummy variable indicating whether living in a major city, state of residence dummies and year dummies. Standard errors clustered at the individual level are reported in parenthesis. ${ }^{*} p<0.1 ;{ }^{* *} p<0.05 ; * * *$ $p<0.01$.

FE estimates are also found to be negative and highly significant but in much smaller

\footnotetext{
${ }^{6}$ We use the STATA command qreg2 written by Machado and Santos Silva (2013) (version 3.4, February 2015) to perform the estimations. The standard STATA command qreg does not allow us to cluster standard errors at group level.
} 
magnitude than OLS estimates, indicating that ignoring unobserved heterogeneity overstates the adverse impact of crime victimisation on subjective well-being. On average, physical violence and property crimes are associated with a decline of respectively 0.30 $(=0.566 / 1.90)$ and $0.03(=0.066 / 1.90)$ standard deviations of the mental well-being measure. Consistent with the OLS estimates, the FE estimates of the average negative impact on mental well-being is still stronger for crimes against the person than for crimes against property. Furthermore, we cannot find evidence in FE estimates that physical violence has a stronger effect on the well-being of females than on the well-being of males. Property crimes are not found to exert differential mean effects on the wellbeing of the two genders.

Table 3: Heterogeneous well-being effects of victimisation (QR-FE estimates)

\begin{tabular}{clllll}
\hline \hline & Q10 & Q25 & Q50 & Q75 & Q90 \\
\hline All & & & & & \\
Physical violence & $-1.089^{* * *}$ & $-0.852^{* * *}$ & $-0.549^{* * *}$ & $-0.248^{* * *}$ & -0.054 \\
& $(0.120)$ & $(0.066)$ & $(0.019)$ & $(0.041)$ & $(0.115)$ \\
Property crime & $-0.145^{* * *}$ & $-0.098^{* * *}$ & $-0.065^{* * *}$ & $-0.033^{* *}$ & -0.012 \\
& $(0.052)$ & $(0.021)$ & $(0.008)$ & $(0.015)$ & $(0.037)$ \\
Male & & & & & \\
Physical violence & $-1.135^{* * *}$ & $-0.752^{* * *}$ & $-0.454^{* * *}$ & $-0.229^{* * *}$ & -0.057 \\
& $(0.124)$ & $(0.092)$ & $(0.048)$ & $(0.045)$ & $(0.102)$ \\
Property crime & $-0.105^{*}$ & $-0.105^{* * *}$ & $-0.058^{* * *}$ & 0.007 & -0.008 \\
& $(0.055)$ & $(0.026)$ & $(0.011)$ & $(0.022)$ & $(0.038)$ \\
Female & & & & & \\
Physical violence & $-1.180^{* * * *}$ & $-0.955^{* * *}$ & $-0.580^{* * *}$ & $-0.258^{* * *}$ & -0.081 \\
& $(0.189)$ & $(0.076)$ & $(0.021)$ & $(0.059)$ & $(0.159)$ \\
Property crime & $-0.186^{* * *}$ & $-0.101^{* * *}$ & $-0.070^{* * *}$ & $-0.060^{* *}$ & -0.018 \\
& $(0.071)$ & $(0.041)$ & $(0.012)$ & $(0.024)$ & $(0.061)$ \\
\hline H0: Male=Female & & & & & \\
Physical violence & $p=0.842$ & $p=0.089$ & $p=0.016$ & $p=0.696$ & $p=0.899$ \\
Property crime & $p=0.367$ & $p=0.934$ & $p=0.461$ & $p=0.040$ & $p=0.889$ \\
\hline
\end{tabular}

Note: Control variables include age, age squared, a married dummy, years of schooling, household income, number of family members, and a dummy variable indicating whether living in a major city, state of residence dummies and year dummies. Standard errors clustered at the individual level are reported in parenthesis. ${ }^{*} p<0.1 ;{ }^{* *} p<0.05 ;{ }^{* * *}$ $p<0.01$.

Table 3 displays the QR-FE results at the 10th, 25th, 50th, 75th and 90th percentiles of the distribution of the SF-36 subjective well-being measure. As opposed to the average case, physical violence has about double the negative impact at the 10th percentile of the well-being distribution, while the effect is not statistically significant at the 90th percentile. 
Similarly, we see a monotonic decrease in the detrimental impact of property crimes over the distribution of subjective well-being. This result corroborates our initial observation that people at the lower end of the well-being distribution feel the impact of crime to a larger extent than people at the higher end. It is quite clear that a focus on the average effects will conceal substantial heterogeneity in the effects of victimisation over the subjective well-being distribution.
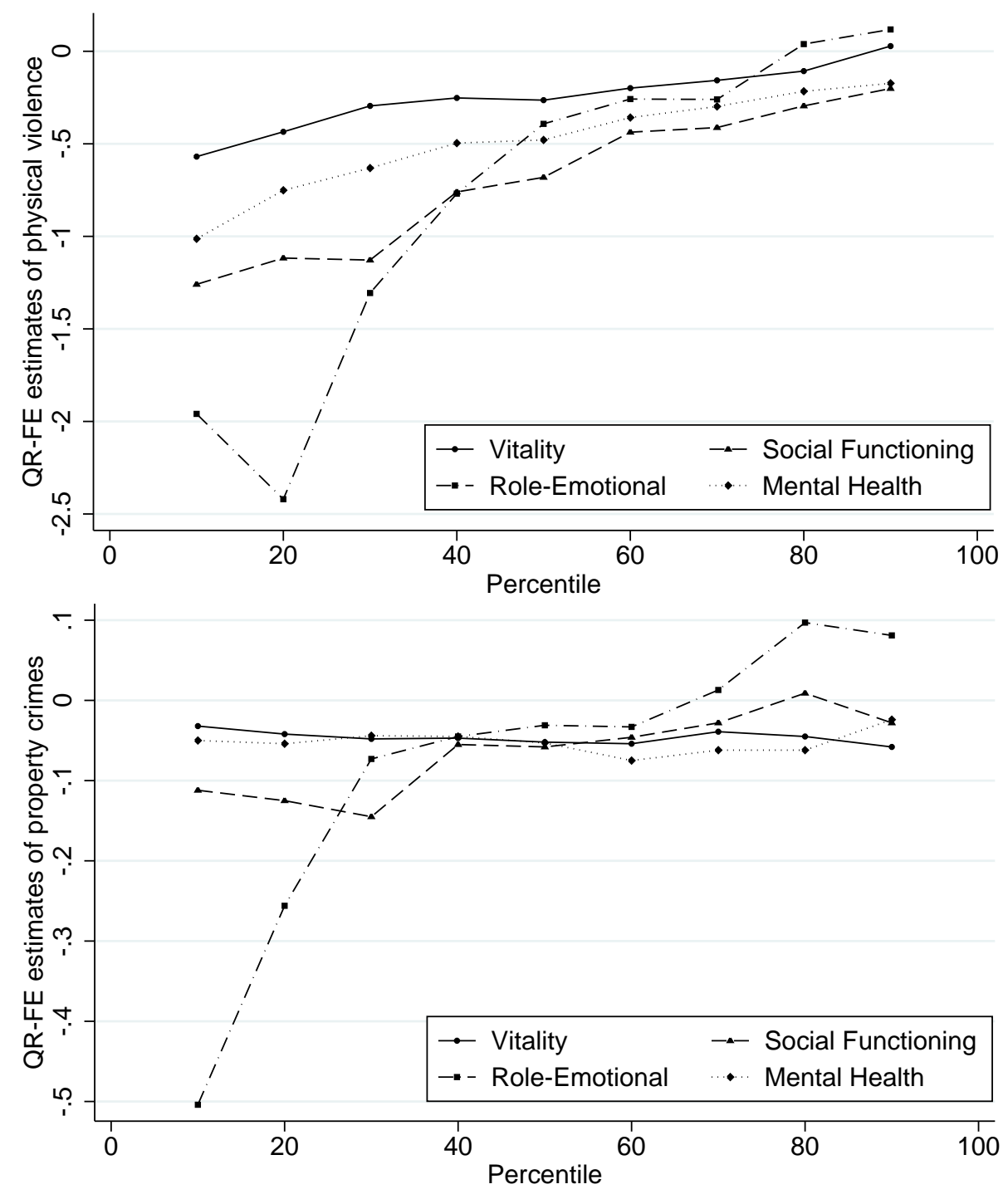

Figure 3: Distributional effects of victimisation on mental well-being components

While we find significant and heterogeneous effects of physical violence and property crimes on the overall subjective well-being in Tables 2 and 3, it is worth going further and investigating each component which make up this multifaceted indicator. Indeed, these heterogeneous effects may be stronger for some aspects of subjective well-being and weaker for 
others. For example, among the four constituents of the SF-36 mental well-being measure, Role-Emotional (RE) measures limitation in work or activities due to emotional health, while quite differently, Mental Health (MH) measures directly feelings of anxiety and depression. We estimated separately the effects of crime victimisation on each constituent of SF-36 mental well-being following the same methodology as we did with the overall SF-36, and illustrate the results at each decile of the well-being distribution in Figure 3.

Consistent with the results reported in Table 3, we find that the effects of physical violence are heterogeneous for each constituent of mental well-being, with much larger negative effects at the bottom part of well-being distribution than at the top end. Among

the four constituents, Vitality (VT) is least affected by physical violence throughout the distribution. Social Functioning (SF) is more negatively affected by physical crimes than Mental Health (MH). The effects of physical violence on Role-Emotional (RE) show the greatest heterogeneity among the four components of mental well-being.

We also find dispersed effects of property crimes on each of the four constituents of the SF-36 mental well-being. Figure 3 shows that the effects of property crimes on Vitality (VT) and Mental Health (MH) are very similar to each other and are stable along the well-being distribution. In contrast, property crimes have heterogeneous effects on both Social Functioning (SF) and Role-Emotional (RE), with greater amplitude at the lower end of the well-being distribution. Similar to the effects of physical violence, the distributional effects of property crimes on Role-Emotional (RE) show the greatest heterogeneity among the four components. In addition, a comparison between physical violence and property crimes shows that the former has larger adverse consequences throughout the distributions of the four constituents of mental well-being.

\subsection{Subjective well-being effects: victimisation compared with other life events}

In this section, we compare the estimated impact of victimisation with that of other negative life events which were reported by individuals surveyed in HILDA, namely: (i) serious personal injury/illness; (ii) fired or made redundant; and (iii) death of spouse or child. Ta- 
ble 4 shows that $7.80 \%$ of the 96,503 observations in our sample reported serious personal injury/illness in the previous year. About 3.40\% of them were fired or made redundant by employers and $0.59 \%$ experienced the death of spouse or children in the past 12 months.

Table 4: Prevalence rates of three other life events

\begin{tabular}{|c|c|c|c|c|c|c|}
\hline & \multicolumn{2}{|l|}{ All } & \multicolumn{2}{|l|}{ Male } & \multicolumn{2}{|c|}{ Female } \\
\hline & Mean & SD & Mean & SD & Mean & SD \\
\hline \multicolumn{7}{|l|}{ Three other life events } \\
\hline (i) Serious personal injury/illness (\%) & 7.80 & 0.27 & 8.09 & 0.27 & 7.54 & 0.26 \\
\hline (ii) Fired or made redundant (\%) & 3.40 & 0.18 & 4.33 & 0.20 & 2.61 & 0.16 \\
\hline (iii) Death of spouse or child (\%) & 0.59 & 0.08 & 0.45 & 0.07 & 0.71 & 0.08 \\
\hline Observations & 96,503 & & 45,164 & & 51,339 & \\
\hline
\end{tabular}

Previous studies have shown that these life events have negative effects on the mean subjective well-being (Clark et al., 2008; Binder and Coad, 2015). We estimate the effects of these three life events on SF-36 mental well-being in Australia, using the same methodology as for victimisation. Table 5 below reports the results.

We find that these three adverse life events all have statistically significant effects on individual mental well-being. Looking at the mean estimates, the impact of physical violence on subjective well-being (with an estimated coefficient of -0.566) ranks below that of personal injuries $(-0.706)$ and the death of spouse or child $(-0.728)$ but is much larger (about 3 times larger) than the effect of being fired or made redundant $(-0.168)$. On the opposite, property crimes have a comparatively small mean effect on well-being, ranking last with an estimated coefficient of -0.066 .

However, similar to what we observe with victimisation, we find that these effects are heterogeneous along the well-being distribution. Their negative impact is mostly felt at the bottom end of the well-being distribution. So much so that most of the difference between the impacts of physical violence, personal injury and the death of a spouse or child occurs below the median of the distribution of well-being. The impact of these life events estimated at the median and the 75th percentile of the well-being distribution do not significantly differ from one another. Significant differences reappear at the 90th percentile where personal injuries and death of a spouse of child still exerting an impact as opposed 
to physical violence.

Table 5: Well-being effects of other life events (FE and QR-FE estimates)

\begin{tabular}{|c|c|c|c|c|c|c|}
\hline & Mean & Q10 & Q25 & Q50 & Q75 & Q90 \\
\hline \multicolumn{7}{|c|}{ (i) Serious personal injury/illness } \\
\hline All & $\begin{array}{l}-0.706^{* * *} \\
(0.024)\end{array}$ & $\begin{array}{l}-1.508^{* * *} \\
(0.049)\end{array}$ & $\begin{array}{l}-1.079^{* * *} \\
(0.027)\end{array}$ & $\begin{array}{l}-0.625^{\text {*** }} \\
(0.018)\end{array}$ & $\begin{array}{l}-0.314^{* * *} \\
(0.015)\end{array}$ & $\begin{array}{l}-0.168^{* * *} \\
(0.026)\end{array}$ \\
\hline Male & $\begin{array}{l}-0.667^{* * *} \\
(0.034)\end{array}$ & $\begin{array}{l}-1.591^{* * *} \\
(0.078)\end{array}$ & $\begin{array}{l}-1.018^{* * *} \\
(0.041)\end{array}$ & $\begin{array}{l}-0.572^{* * *} \\
(0.024)\end{array}$ & $\begin{array}{l}-0.268^{* * *} \\
(0.020)\end{array}$ & $\begin{array}{l}-0.131^{* * *} \\
(0.038)\end{array}$ \\
\hline Female & $\begin{array}{l}-0.741^{* * *} \\
(0.035)\end{array}$ & $\begin{array}{l}-1.433^{* * *} \\
(0.060)\end{array}$ & $\begin{array}{l}-1.121^{* * *} \\
(0.041)\end{array}$ & $\begin{array}{l}-0.681^{* * *} \\
(0.017)\end{array}$ & $\begin{array}{l}-0.359^{* * *} \\
(0.023)\end{array}$ & $\begin{array}{l}-0.199^{* * *} \\
(0.040)\end{array}$ \\
\hline \multicolumn{7}{|c|}{ (ii) Fired or made redundant } \\
\hline All & $\begin{array}{l}-0.168^{* * *} \\
(0.031)\end{array}$ & $\begin{array}{l}-0.486^{* * *} \\
(0.068)\end{array}$ & $\begin{array}{l}-0.289^{* * *} \\
(0.051)\end{array}$ & $\begin{array}{l}-0.100^{* * *} \\
(0.017)\end{array}$ & $\begin{array}{l}-0.051^{* *} \\
(0.020)\end{array}$ & $\begin{array}{l}0.028 \\
(0.038)\end{array}$ \\
\hline Male & $\begin{array}{l}-0.146^{* * *} \\
(0.038)\end{array}$ & $\begin{array}{l}-0.483^{* * *} \\
(0.071)\end{array}$ & $\begin{array}{l}-0.241^{* * *} \\
(0.047)\end{array}$ & $\begin{array}{l}-0.080^{* * *} \\
(0.019)\end{array}$ & $\begin{array}{l}-0.024 \\
(0.020)\end{array}$ & $\begin{array}{l}0.070 \\
(0.043)\end{array}$ \\
\hline Female & $\begin{array}{l}-0.204^{* * *} \\
(0.051)\end{array}$ & $\begin{array}{l}-0.524^{* * *} \\
(0.084)\end{array}$ & $\begin{array}{l}-0.362^{* * *} \\
(0.044)\end{array}$ & $\begin{array}{l}-0.133^{* * *} \\
(0.028)\end{array}$ & $\begin{array}{l}-0.020 \\
(0.039)\end{array}$ & $\begin{array}{l}0.090 \\
(0.055)\end{array}$ \\
\hline \multicolumn{7}{|c|}{ (iii) Death of spouse or child } \\
\hline All & $\begin{array}{l}-0.728^{* * *} \\
(0.087)\end{array}$ & $\begin{array}{l}-1.380^{* * *} \\
(0.131)\end{array}$ & $\begin{array}{l}-1.114^{* * *} \\
(0.125)\end{array}$ & $\begin{array}{l}-0.590^{* * *} \\
(0.055)\end{array}$ & $\begin{array}{l}-0.373^{* * *} \\
(0.071)\end{array}$ & $\begin{array}{l}-0.304^{* *} \\
(0.117)\end{array}$ \\
\hline Male & $\begin{array}{l}-0.564^{* * *} \\
(0.116)\end{array}$ & $\begin{array}{l}-0.993^{* * *} \\
(0.451)\end{array}$ & $\begin{array}{l}-0.614^{* * *} \\
(0.124)\end{array}$ & $\begin{array}{l}-0.431^{* * *} \\
(0.066)\end{array}$ & $\begin{array}{l}-0.243^{\text {*** }} \\
(0.064)\end{array}$ & $\begin{array}{l}-0.208^{*} \\
(0.112)\end{array}$ \\
\hline Female & $\begin{array}{l}-0.873^{* * *} \\
(0.118)\end{array}$ & $\begin{array}{l}-1.566^{* * *} \\
(0.237)\end{array}$ & $\begin{array}{l}-1.225^{\text {*** }} \\
(0.141)\end{array}$ & $\begin{array}{l}-0.717^{* * *} \\
(0.049)\end{array}$ & $\begin{array}{l}-0.432^{* * *} \\
(0.096)\end{array}$ & $\begin{array}{l}-0.435^{* *} \\
(0.212)\end{array}$ \\
\hline
\end{tabular}

Note: Control variables include age, age squared, a married dummy, years of schooling, household income, number of family members, and a dummy variable indicating whether living in a major city, state of residence dummies and year dummies. Standard errors clustered at the individual level are reported in parenthesis. ${ }^{*} p<0.1 ;{ }^{* *} p<0.05 ; * * *$ $p<0.01$.

\subsection{Robustness checks}

\subsubsection{Does sample attrition affect the well-being effects of victimisation?}

The longitudinal nature of the HILDA Survey allows us to address the bias due to unobserved individual heterogeneity in our estimations. However, one potential drawback of using panel estimator is sample attrition. People drop out of the panel survey due to various reasons such as refusal to respond, death or inability of survey team to locate them. It could even be that the people worst affected by crime drop out of the survey. If the characteristics of persons and households that attrite from HILDA are systematically 
different from those of people who remain, then our analyses that do not account for the possible selective nature of sample attrition may lead to biased estimates.

The issue of attrition in HILDA is well documented and has been the subject of a number of studies. Using the first few waves of HILDA, Watson and Wooden (2004) concur with Fitzgerald et al. (1998) that attrition is likely to affect constant terms rather than having a significant effect on the coefficient estimates in a regression context, can be applicable to the HILDA sample. They conclude that "for the first few waves at least, any bias is likely to be relatively small" (page 307). Further studies by Watson and Wooden $(2006,2007)$ find that there is a very large random component to non-response in HILDA and attrition bias appears to be small. Furthermore, Cai and Waddoups (2011) corroborate this finding in their analysis of union wage effects using HILDA.

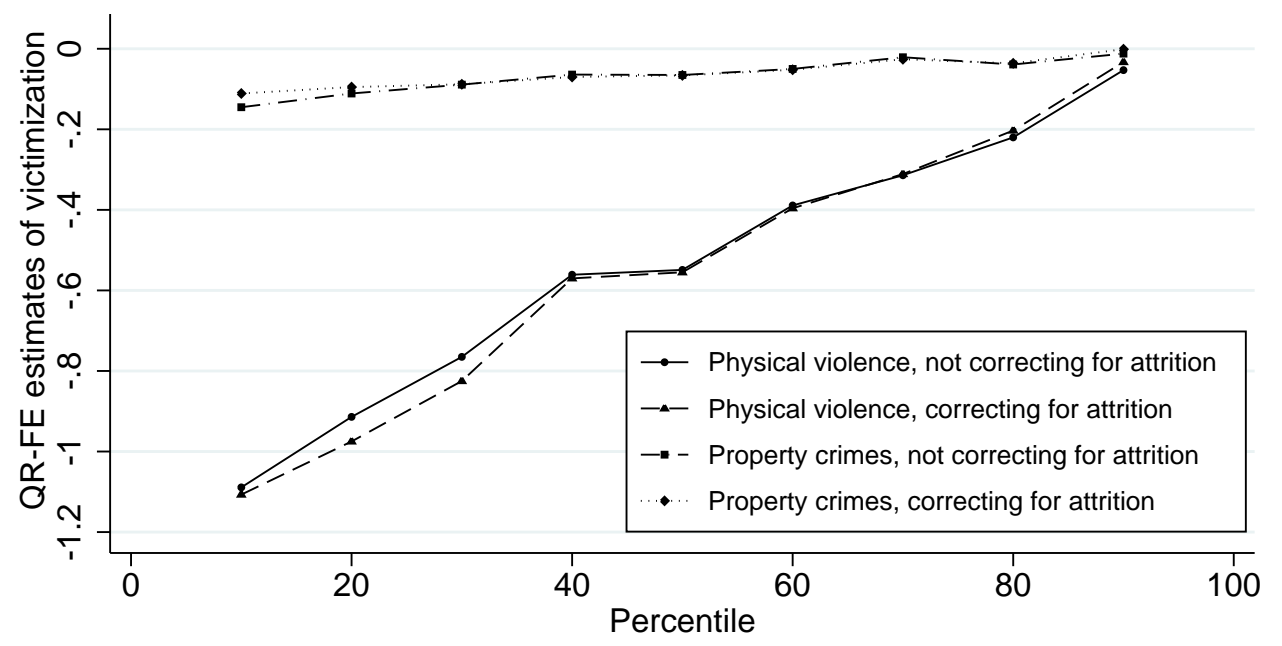

Figure 4: Effects of victimisation, correcting and not correcting for attrition bias

In spite of these encouraging findings, we check whether attrition should be considered as a problem in the context of our study. We run both our FE and QR-FE models using the longitudinal weights available in HILDA that can be used to overcome the bias due to survey non-response and attrition (Watson and Wooden, 2004; Wilkins, 2014). We find that when the attrition bias has been corrected with sample weights, the FE coefficient estimates of physical violence and property crimes are very similar to those obtained in the original models. With regards to whether or not sample attrition affects the QR-FE coefficients estimates at each decile of the well-being distribution, our results, depicted in 
Figure 4, show that sample attrition has very trivial effects on our original findings. ${ }^{7}$

\subsubsection{Using alternative measures of subjective well-being}

It can be argued that the strong results we have obtained on the effects of crime victimisation on individuals' well-being may be partly due to how we measure well-being. We test this proposition by using alternative definitions of individuals' well-being as the dependent variable in the models. In each wave of HILDA, respondents were asked to rate their overall life satisfaction on a Likert scale of 0 (very dissatisfied) to 10 (very satisfied). Life satisfaction measure has been used as a measure of general subjective well-being in many studies such as Clark et al. (2008), Kuroki (2013) and Staubli et al. (2014). Respondents were also asked to report their satisfaction with different domains of life such as employment opportunities, family relationship, amount of free time, etc. One variable of particular interest for this study is people's rating to the question of how safe they feel. Crime victimisation is highly likely to change people's subjective feelings of safety. We opt to use both life satisfaction and safety satisfaction as alternative measures of subjective well-being in order to check the robustness of our findings.

Table 6 reports the subjective well-being distributions found in HILDA by victimisation status for the two alternative definitions of subjective well-being. On average, crime victims are less satisfied with their life and safety than non-victims. A rough comparison also indicates that physical violence may be more detrimental to people's happiness than property crimes. Crime victims have higher propensity to report low levels of life satisfaction (such as 0, 1, 2, and 3) than non-victims, and they are less likely to report high levels of life satisfaction (such as 8, 9 and 10). In general, Table 6 shows similar patterns of subjective well-being distributions of crime victims and non-victims to those revealed in Figure 1 when subjective well-being is measured through the SF-36 index.

We use life satisfaction and safety satisfaction variables as dependent variables in our

\footnotetext{
${ }^{7}$ Using an approach similar to that the one in Cai and Waddoups (2011), we run a FE panel regression of attrition at time $t$ on victimisation status at $t-1$, controlling for the covariates used in the subjective well-being model. We find no evidence that crime victims are more likely to attrite from the survey than non-victims, suggesting that the potential bias due to different attrition by victimisation status is probably not of big concern.
} 
Table 6: Subjective well-being distribution by victimisation status (\%)

\begin{tabular}{|c|c|c|c|c|c|c|c|c|}
\hline & \multicolumn{4}{|c|}{ Satisfaction with life } & \multicolumn{4}{|c|}{ Satisfaction with safety } \\
\hline & \multicolumn{2}{|c|}{ Physical violence } & \multicolumn{2}{|c|}{ Property crime } & \multicolumn{2}{|c|}{ Physical violence } & \multicolumn{2}{|c|}{ Property crime } \\
\hline & Yes & No & Yes & No & Yes & No & Yes & No \\
\hline 0 & 1.66 & 0.08 & 0.36 & 0.09 & 2.13 & 0.15 & 0.74 & 0.15 \\
\hline 1 & 1.20 & 0.15 & 0.40 & 0.16 & 1.73 & 0.19 & 0.91 & 0.18 \\
\hline 2 & 2.20 & 0.37 & 0.70 & 0.38 & 2.46 & 0.45 & 1.35 & 0.43 \\
\hline 3 & 3.66 & 0.70 & 1.41 & 0.71 & 4.66 & 0.79 & 2.24 & 0.78 \\
\hline 4 & 3.26 & 1.16 & 2.07 & 1.15 & 4.32 & 1.23 & 3.21 & 1.18 \\
\hline 5 & 11.51 & 4.06 & 5.68 & 4.10 & 9.58 & 4.15 & 7.14 & 4.09 \\
\hline 6 & 10.65 & 6.19 & 8.93 & 6.13 & 7.58 & 4.83 & 6.65 & 4.78 \\
\hline 7 & 24.68 & 20.99 & 23.55 & 20.92 & 14.97 & 14.21 & 17.34 & 14.06 \\
\hline 8 & 23.35 & 35.33 & 32.00 & 35.31 & 22.29 & 30.24 & 27.60 & 30.24 \\
\hline 9 & 11.11 & 21.28 & 17.76 & 21.29 & 15.90 & 25.18 & 19.13 & 25.34 \\
\hline 10 & 6.72 & 9.69 & 7.14 & 9.77 & 14.37 & 18.58 & 13.69 & 18.76 \\
\hline Total & 100.00 & 100.00 & 100.00 & 100.00 & 100.00 & 100.00 & 100.00 & 100.00 \\
\hline Mean & 6.78 & 7.83 & 7.48 & 7.83 & 7.01 & 8.12 & 7.50 & 8.13 \\
\hline Observations & 1,503 & 95,000 & 4,735 & 91,678 & 1,503 & 95,000 & 4,735 & 91,678 \\
\hline
\end{tabular}

FE and QR-FE estimations. ${ }^{8}$ The two dependent variables are categorical variables on an eleven-point Likert scale (0-10). They can be considered as approximately continuous and used in quantile regressions. Indeed, using data from the British Household Panel Survey (BHPS), Binder and Coad $(2011,2015)$ show that even when their subjective wellbeing measure is categorical on a seven-point Likert scale (1-7), quantile regressions can still uncover heterogeneous effects of covariates on different parts of subjective well-being distribution.

Table 7 reports the FE and QR-FE estimates. We find very similar results to those reported in Tables 3 and 4. The main findings are: (i) On average, both physical violence and property crimes reduce people's satisfaction with life, and we find the average negative impact on life satisfaction to be much stronger for crimes against the person than for crimes against property; (ii) The effects of physical violence and property crimes are highly

\footnotetext{
${ }^{8}$ One concern of using measures of this type is their interpersonal comparability, as survey respondents may interpret and use the response categories differently $(\mathrm{Ng}, 1997)$. When using the FE and QR-FE estimation, we do not need to assume that the answers to satisfaction questions are fully interpersonally comparable because the individual fixed effects $\left(u_{i}\right)$ can adequately deal with this issue. In addition, the use of the linear specification assumes cardinality in satisfaction answers, which means that we have to assume that the difference in satisfaction between a three and a four for any individual is the same as between a five and a six for any other individual. Ferrer-i Carbonell and Frijters (2004) find that cardinality assumption generally does not lead to different conclusions.
} 


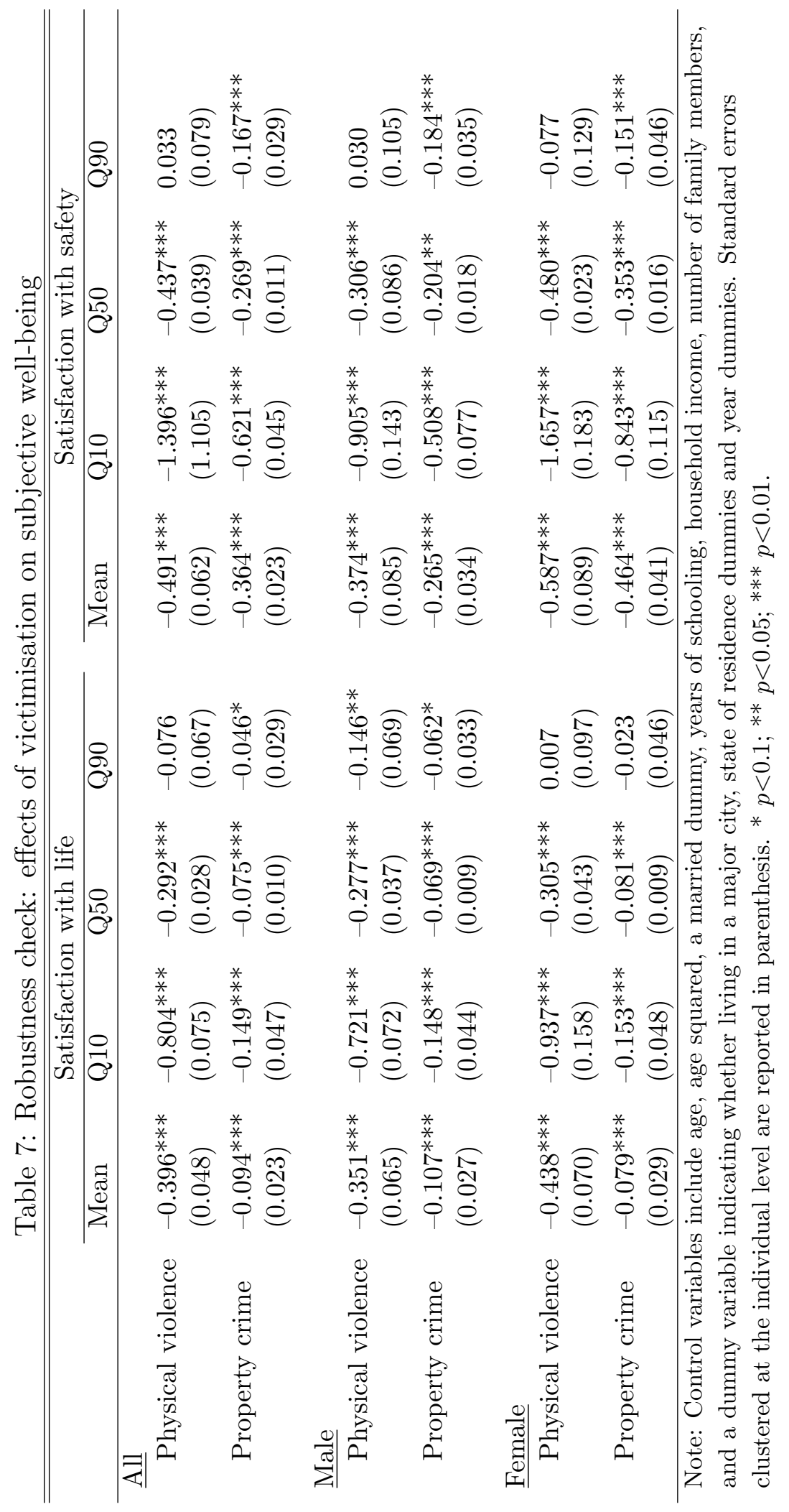


heterogeneous with much larger impact in the lower part of the life satisfaction distribution than at the higher end; (iii) Both physical violence and property crimes affect people's happiness with safety negatively, and the impact decreases along the distribution of safety satisfaction; and (iv) Physical violence and property crimes adverseimpact satisfaction with safety to a larger extent than for life satisfaction. One possible explanation for this finding is that the overall life satisfaction is a global conception of well-being that aggregates the happiness with different domains of life (van Praag et al., 2003), and happiness with safety, one of the many domains of life, is a very important channel through which crimes victimisation affects life satisfaction. ${ }^{9}$

\subsubsection{Have individuals experienced declined subjective well-being before vic- timisation?}

Although our estimations address the endogeneity bias arising from unobserved individual heterogeneity, they cannot address the bias that could arise from the possible reverse causality between crime victimisation and subjective well-being. If individuals who have experienced a negative shock to subjective well-being are more likely to become victims of crimes, then we may have overestimated the negative consequences of crime victimisation for subjective well-being. In this section, we test whether we observe significant declines in subjective well-being prior to crime victimisation. Namely, we test whether crime victimisation is a predictable event or not. ${ }^{10}$

We run FE panel regressions of subjective well-being measures on a set of dummy

\footnotetext{
${ }^{9}$ To assess the degree to which the negative effect of victimisation on happiness can be explained by the associated declines in happiness with safety, we re-estimate the life satisfaction equation using satisfaction with safety as an additional control in the FE and QR-FE regressions. We find around one third of the average negative effect of physical violence on life satisfaction can be attributed to its negative impact on feelings of safety. Throughout the distribution of life satisfaction, the rising feelings of insecurity after physical violence can explain about $16 \%$ to $38 \%$ of the declines in life satisfaction. In contrast, the mean and distributional effects of property crimes on life satisfaction become insignificant after controlling for safety satisfaction, suggesting that the decreasing subjective well-being due to property crimes are solely driven by the deteriorating happiness about safety. A note of caution needs to be issued regarding the above findings as safety satisfaction is an endogenous variable when included in life satisfaction estimation. Ideally, we want to address the endogeneity problem of safety satisfaction using instrumental variable estimation. A valid instrument that is highly correlated with safety satisfaction but not correlated with life satisfaction is unavailable in HILDA.

${ }^{10}$ The approach we take here is similar to the ones used in Clark et al. (2008) and Cornaglia et al. (2014) for examining the dynamic well-being effects of life events.
} 


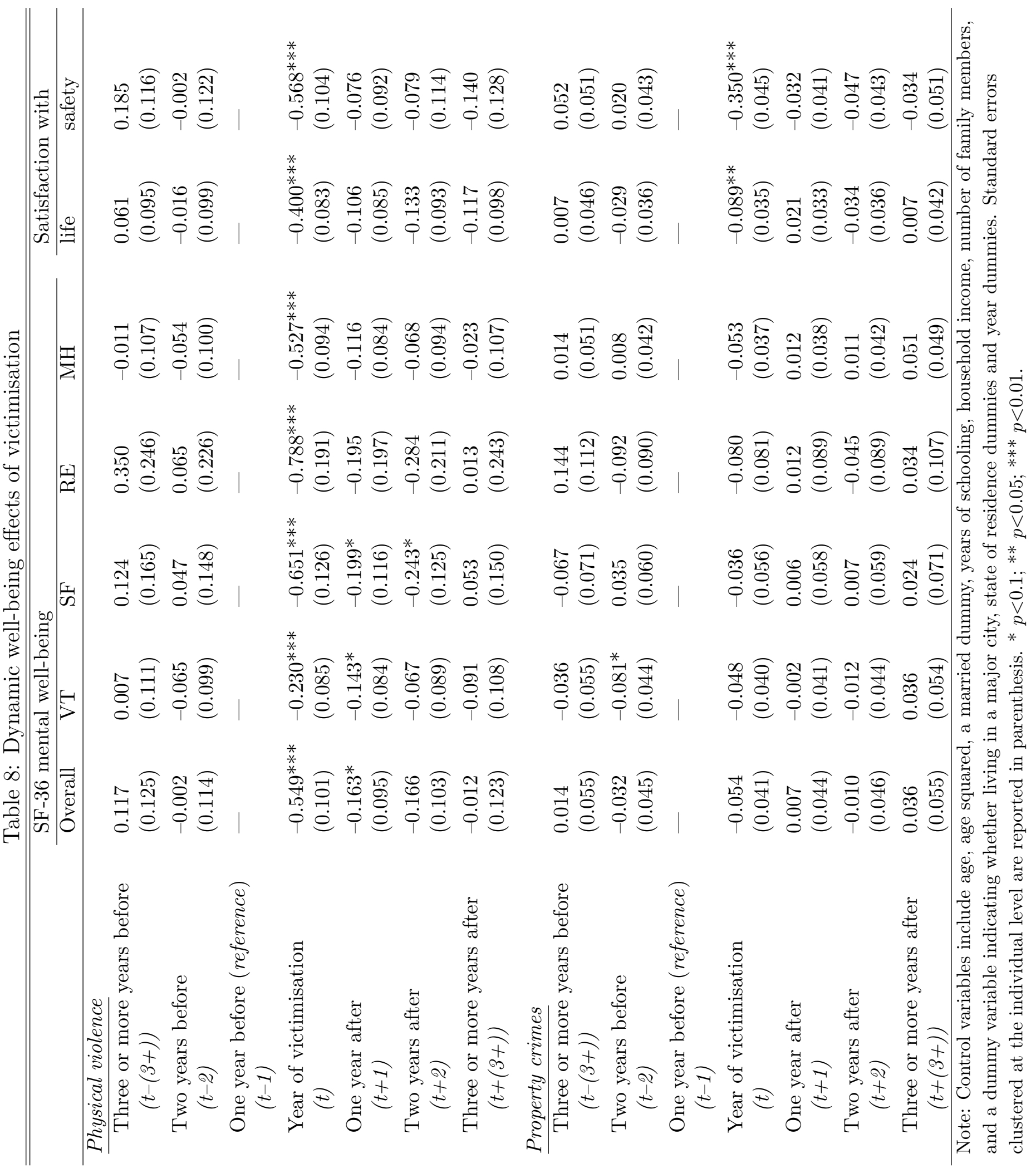


variables indicating one year, two years, three and more years before and after the year when crime victimisation happened. The logic of our approach is that if there is a decline in subjective well-being prior to crime victimisation, the well-being effect of the dummy indicating two years prior to victimisation $(t-2)$ on mental well-being (at time $t$ ) should be statistically different from the well-being effect of the dummy indicating one year before victimisation $(t-1)$. Among all the year dummies, we select the dummy indicating one year before the victimisation $(t-1)$ as the reference category. To our purpose of detecting whether there is a drop in subjective well-being before victimisation happens, we only need to test whether the estimated coefficient of year dummy $(t-2)$ has a positive sign and whether it is statistically significant.

Table 8 report the results of these tests. We find no evidence, on both types of well-being measures, that the coefficient on $(t-2)$ dummy is both positive and statistically significant (relative to the reference $(t-1)$ dummy). Thus, we find no evidence that people's subjective well-being becomes significantly lower prior to victimisation. What makes this conclusion more convincing is that the coefficient estimate of the year dummy indicating three or more years before the incident $(t-(3+))$ is also not statistically significant. This finding corroborates the previous speculations by Powdthavee (2005), Davies and Hinks (2010) and Staubli et al. (2014) that it is intuitively implausible that subjective well-being affects victimisation in an adult population.

Consistent with our expectation, Table 8 shows that there is a significant difference in subjective well-being between the year prior to victimisation and the year of victimisation. The dynamic results provided in Table 8 indicate the negative impact of crime victimisation on subjective well-being is transitory. Crime victims experience a significant decline in subjective well-being throughout year following victimisation. They then will restore to pre-victimisation level one year after the event. Using data from the German Socio-Economic Panel, Clark et al. (2008) examine the dynamic effects of many life events such as marriage, divorce, widowhood, child birth and layoff on people's life satisfaction and they find evidence of complete adaptation to these life events in a short time span. We find similar evidence of adaptation in people's subjective well-being to crime victimisation. 


\section{Conclusion}

This paper estimates the effects of crime victimisation on subjective well-being, using data from the longitudinal Household, Income and Labour Dynamics in Australia (HILDA) survey. Using fixed effects panel estimations, our analysis shows that both physical violence and property crimes negatively affect the subjective well-being of Australians. We find that the average effect is much stronger for physical violence than for property crimes. On average, physical violence and property crimes are associated with a decline of respectively 0.30 and 0.03 standard deviation on the SF-36 mental well-being scale. Using recently developed panel data quantile regression model with fixed effects, we find strong evidence of heterogeneous links between crime victimisation and happiness. The adverse effects of both physical violence and property crimes are most strongly felt at the lower end of the distribution of well-being.

Comparing the well-being effects of physical attacks and property crimes with three other life events (i) serious personal injury/illness; (ii) fired or made redundant; and (iii) death of spouse or child, we find that physical violence is much more distressing than being fired. While we find the mean effect of violent crimes to be smaller than that of personal injury/illness and the death of a spouse or child, we also find that these three life events are much closer than originally seems when one accounts for the heterogeneity of the effects along the well-being distribution. Indeed, most of the differences are observed in lower deciles of the distribution where the effects are stronger while the magnitude of the effects is much more concentrated above the median of the distribution. Accounting for the distributional heterogeneity of the effects of crime illustrates the highly damaging effect of violent crimes on people at the lower end of the well-being distribution. By contrast, we find that the distributional negative well-being effects of property crimes to be relatively small.

Our findings of adverse effects of victimisation on subjective wellbeing are robust to (i) the correction of sample attrition in HILDA and (ii) the usage of alternative well-being measures (life satisfaction and safety satisfaction) as dependent variables. Furthermore, we cannot find evidence that the negative well-being effects of crime victimisation are driven 
by reverse causality (in which case people may experience a negative shock to subjective well-being before becoming crime victims).

An important result of this study is that the negative effects of crime on well-being are intense but short-lived, to an extent that is similar to all other negative (and positive) life events (Clark et al., 2008). People adapt. However, this is not to say that before they do adapt, the adverse consequences of crime on well-being are likely to snowball into further negative outcomes, having themselves further consequences on individuals' well-being. For instance, using the same data, Fritjers et al. (2014) find that a one standard deviation decrease in mental health leads to 30 percentage point decrease in employment. We do find that violent crime decreases well-being by 0.30 standard deviation, suggesting that the employment effect of experiencing violent crimes may be in the magnitude of 10 percentage points.

The findings reported in this paper have important policy implications. Non-pecuniary costs of crime such as psychological well-being losses of victims should be taken into consideration by policy makers, in addition to pecuniary costs such as financial losses and medical expenses. From the policy perspective, the consideration of the previously unmeasured cost of crime strengthens the case for public spending to combat crime. Furthermore, crime leads to important shocks to individual subjective well-being which could be offset, would victims be provided with adequate professional support following such traumatic life events. This is an area where public policy can potentially increase its involvement over and beyond its usual roles of crime prevention and financially compensating victims.

\section{References}

Atkeson, B. M., K. S. Calhoun, P. A. Resick, and E. M. Ellis (1982). "Victims of rape: Repeated assessment of depressive symptoms". Journal of Consulting and Clinical Psychology 50, 96-102.

Binder, M. and A. Coad (2011). "From Average Joe's happiness to Miserable Jane and 
Cheerful John: using quantile regressions to analyze the full subjective well-being distribution". Journal of Economic Behavior \& Organization 79, 275-290.

Binder, M. and A. Coad (2015). "Heterogeneity in the relationship between unemployment and subjective well-being: A quantile approach". Economica, forthcoming. Doi: 10.1111/ecca. 12150 .

Cai, L. and J. Waddoups (2011). "Union wage effects in Australia: Evidence from panel data". British Journal of Industrial Relations 49, s279-s305.

Canay, A. I. (2011). "A simple approach to quantile regression for panel data". Econometrics Journal 14, 368-386.

Chatterji, P., M. Alegria, M. Lu, and D. Takeuchi (2007). "Psychiatric disorders and labor market outcomes: Evidence from the National Latino and Asian American Study". Health Economics 16, 1069-1090.

Chatterji, P., M. Alegria, and D. Takeuchi (2011). "Psychiatric disorders and labor market outcomes: Evidence from the National Comorbidity Survey-Replication". Journal of Health Economics 30, 858-868.

Clark, A. E., E. Diener, Y. Georgellis, and R. E. Lucas (2008). "Lags and leads in life satisfaction: A test of the baseline hypothesis". Economic Journal 118, F222-F243.

Clogg, C. C., E. Petkova, and A. Haritou (1995). "Statistical methods for comparing regression coefficients between models". American Journal of Sociology 100, 1261-1293.

Cohen, M. A. (2008). "The effect of crime on life satisfaction". Journal of Legal Studies 37, S325-S353.

Cornaglia, F., N. E. Feldman, and A. Leigh (2014). "Crime and mental well-being". Journal of Human Resources 49, 110-140.

Davies, S. and T. Hinks (2010). "Crime and happiness amongst heads of households in Malawi". Journal of Happiness Studies 11, 457-476. 
Davis, R. and L. Friedman (1985). "The emotional aftermath of crime and violence". In C. Figley (Ed.), Trauma and Its Wake: The Study and Treatment of Post-traumatic Stress Disorder. New York: Brunner/Mazel.

Dustmann, C. and F. Fasani (2015). "The effect of local area crime on mental health". Economic Journal, forthcoming. Doi: 10.1111/ecoj.12205.

Ferrer-i Carbonell, A. and P. Frijters (2004). "How important is methodology for the estimates of the determinants of happiness?". Economic Journal 114, 641-659.

Fitzgerald, J., P. Gottschalk, and R. Moffitt (1998). "An analysis of sample attrition in panel data: The Michigan Panel Study of Income Dynamics". Journal of Human Resources 33, 251-299.

Flatau, P., J. Galea, and R. Petridis (2000). "Mental health and wellbeing and unemployment". Australian Economic Review 2, 161-181.

Fritjers, P., D. W. Johnston, and M. A. Shields (2014). "The effect of mental health on employment: Evidence from Australian panel data". Health Economics 23, 1058-1071.

Hamilton, V. H., P. Merrigan, and E. Dufresne (1997). "Down and out: estimating the relationship between mental health and unemployment". Health Economics 6, 397-406.

Hanslmaier, M. (2013). "Crime, fear and subjective well-being: How victimization and street crime affect fear and life satisfaction". European Journal of Criminology 10, 515533.

Hays, R., C. Sherbourne, and R. Mazel (1993). "The rand 36-item health survey 1.0". Health Economics 3, 217-227.

Hemingway, H., M. Stafford, S. Stansfeld, M. Shipley, and M. Marmot (1997). "Is the SF-36 a valid measure of change in population health? Results from the Whitehall II Study". British Medical Journal 315, 1273-1279.

Koenker, R. and G. Bassett (1978). "Regression quantiles". Econometrica 46, 33-50. 
Kuroki, M. (2013). "Crime victimization and subjective well-being: Evidence from happiness data". Journal of Happiness Studies 14, 783-794.

Machado, J. and J. Santos Silva (2013). "Quantile regression and heteroskedasticity". Working paper.

Moller, V. (2005). "Resilient or resigned? Criminal victimization and quality of life in South Africa". Social Indicators Research 72, 263-317.

Moore, S. C. (2006). "The value of reducing fear: An analysis using the European Social Survey". Applied Economics 38, 115-117.

Ng, Y. (1997). "A case for happiness, cardinalism, and interpersonal comparability". Economic Journal 10\%, 1848-1858.

Norris, F. and K. Kaniasty (1992). "A longitudinal study of the effects of various crime prevention strategies on criminal victimization, fear of crime, and psychological distress". American Journal of Community Psychology 20, 625-648.

OECD (2010). OECD Factbook 2009. Paris: Organisation for Economic Co-operation and Development (OECD).

Ojeda, V. D., R. G. Frank, T. G. McGuire, and T. P. Gilmer (2010). "Mental illness, nativity, gender and labor supply". Health Economics 19, 396-421.

Powdthavee, N. (2005). "Unhappiness and crime: Evidence from South Africa". Economica 72, 531-547.

Ross, C. (1993). "Fear of victimization and health". Journal of Quantitative Criminology 9, $159-175$.

Staubli, S., M. Killias, and B. S. Frey (2014). "Happiness and victimization: An empirical study for Switzerland". European Journal of Criminology 11, 57-72.

van Praag, B., P. Frijters, and A. F. i Carbonell (2003). "The anatomy of subjective well-being". Journal of Economic Behavior $\&$ Organization 51, 29-49. 
Watson, N. and M. Wooden (2004). "Sample attrition in the HILDA survey". Australian Journal of Labour Economics 7, 293-308.

Watson, N. and M. Wooden (2006). "Identifying factors affecting longitudinal survey response". Paper Presented at the Methodology of Longitudinal Surveys Conference, University of Essex, Colchester, UK, 12-14 July.

Watson, N. and M. Wooden (2007). "The HILDA Survey and its contribution to economic and social research (so far)". Economic Record 83, 208-231.

Wilkins, R. (2014). Families, Incomes and Jobs, Volume 9: A Statistical Report on Waves 1 to 11 of the Household, Income and Labour Dynamics in Australia Survey. Melbourne Institute of Applied Economic and Social Research, University of Melbourne. 